\title{
South Korean male footballers' involuntary labor migration: Why do they leave for Southeast Asia?
}

\author{
Wangsung Myung* \\ Department of Adapted Physical Education, Hanshin University, Gyeonggi, Korea
}

\begin{abstract}
[Purpose] This study aims to explore migration factors of Korean male footballers who have moved from South Korea to Southeast Asian countries. [Methods] Qualitative case study was conducted with 9 footballers, 4 their agents and $2 \mathrm{~K}$-league staffs as the participant. [Results] As a result, by regarding their migration as involuntary decision, this study could provide academic and practical discussion on sport labor migration. First of all, this study established theoretical framework for involuntary migration of the participants through 'Push-Pull Theory' which focuses on demand and supply on the labor force. Second, this study found that a local rule (FA compensation system) of Korean professional football league (K league) and hierarchical collectivist culture contributed to their migration, which has not been reported by previous studies focused on the voluntary migration of mainstream players and it reflected local context of $\mathrm{K}$ league. [Conclusions] In conclusion, this study confirmed that sport labor migration was also considered as social phenomenon and reflected a cross section of a particular society. Through the migration of athletes, we can provide a variety of viewpoint on economic (market) structure, related policy and system in a particular society, and understand migration motives in terms of agency (subculture).
\end{abstract}

Key words: Sport labor migration, Involuntary migration, K league, Southeast Asian football league, footballer, Transfer, Qualitative case study

\section{서 론}

오늘날 세계화 현상은 스포츠 상업화와 함께 프로스포츠 시장의 양적 및 질적 성장에 크게 기여하였다. 그중 초국가 적 프로스포츠구단들은 경기력 향상과 마케팅 효과의 극대 화를 위해 국외 선수 자원을 적극적으로 활용하였다. 예를 들면, 자국 선수로 구성하기 힘든 특정 역할(포지션)을 해외 선수로 대체함으로써 구단의 경기수행능력을 향상시키고,

논문 투고일 : 2021.03.23.

논문 수정일 : 2021.05.06.

게재 확정일 : 2021.05.31.

* 교신저자 : 명왕성(pluto0706@hs.ac.kr)

* 이 논문은 한신대학교 학술연구비 지원에 의하여 연구되었음.
TV 중계권 및 구단 관련 상품을 판매하기 위해 시장 잠재성 이 높은 국가의 선수를 영입하기도 한다.

한국 프로축구리그(이하 K리그)는 1983년에 출범하였으 며, 1990년대 중후반부터 한국 선수들의 해외 이주가 활성 화 되었다. 초기에는 일본 J리그로의 이주가 지배적이었으 며, 2002년 월드컵 이후 유럽 국가로의 이주가 본격적으로 시작되었다(Myung \& Lee, 2018). 이후 2010년 남아공 월 드컵과 2012년 런던 올림픽을 거치면서 유럽 국가 및 일본 으로의 이주는 한국 선수들의 일반적인 이주 경로가 되었다.

그러나 2014년 이후 K리그 이적 시장에는 상당한 변화가 감지되고 있다. 상당수의 국가대표팀 선수들이 중국 및 중동 국가로, 비(非)국가대표팀 선수들이 동남아시아 국가로 이주 하는 사례가 급증한 것이 그 특징이다. 언론에서는 이러한 
현상을 ‘ $\mathrm{K}$ 리그 엑소더스’로 표현하였다(Kim, 2015, Jul 11; Lee, 2105, Jul 14; Lim, 2015, Jul 16). 일본 및 유럽 국가로의 이주가 일반적이었던 과거와 달리 중국, 중동, 동 남아시아 등 오랜 기간 약소한 축구리그로 평가되어온 국가 로의 이주를 부정적으로 해석한 것이다.

이렇듯 한국 프로축구선수들의 아시아 국가로의 이주 현 상이 두드러지면서 한국의 스포츠 노동 이주는 그 경로와 패 턴에 다양한 변화를 경험하고 있다. 본 연구에서는 이를 새 로운 사회 현상으로 규정하고 한국 프로축구선수들의 이주 사례를 통해 스포츠 노동 이주와 관련된 학술적 및 실천적 논 의를 제공하고자 한다.

특히, 본 연구는 모든 이주 국가를 다룰 수 없다는 한계점 을 인지하고, 동남아시아 국가로의 이주 사례에 한정하여 이 주 요인과 그 의의를 살펴보고자 한다. 동남아시아 국가는 앞서 언급한 ' $\mathrm{K}$ 리그 엑소더스' 현상의 주요 목적지이며 그 주체는 $\mathrm{K}$ 리그 내 비주류선수로서, 이는 그동안 스포츠 노동 이주 연구로부터 관심을 받지 못한 주제이다. 2019년 기준, 동남아시아 프로축구 1 부 리그에서 활동 중인 한국인 선수 는 태국 14 명, 말레이시아 9명, 인도네시아 6명, 베트남 3 명, 인도 3명, 필리핀 3명, 싱가포르 2명, 미얀마 1명 등이며 (transfermartk.com 참고), 하부리그까지 포함하면 그 숫 자는 이상일 것으로 예상된다.

그동안 한국 스포츠 선수들의 해외 노동 이주에 관한 연구 는 사실상 학계로부터 주목을 받지 못했다. 스포츠 노동 이 주에 대한 연구가 적지 않게 수행되었음에도 불구하고 (1) 한 국으로 이주한 외국인 선수의 사회문화적 경험; (2) 스포츠 선수의 이주에 관한 팬들의 인식 그리고 (3) 언론보도 행태가 주요 관심사였다(Ahn \& Kang, 2016; Jo, 2011; Jo, 2014; Jo, Maeng, Lee, 2014; Kim, 2016; Kim, Moon \& Kim, 2014; Lee, 2010; Lee, 2012; Myung \& Lee, 2018; Yang \& Won, 2007).

이에 대해 본 연구에서는 크게 두 가지의 원인을 가늠해 볼 수 있다. 첫째, 그동안 한국 프로스포츠 선수들이 동시다 발적으로 특정 국가 또는 리그로 이동하는 현상이 부재했기 때문에 연구 주제로서 주목받지 못했을 것이다. 둘째, 해외 로 이적한 한국 스포츠선수들을 연구 참여자로 선정하는데 적지 않은 제약이 있었을 것으로 판단된다. 하지만 2014년 을 기점으로 $\mathrm{K}$ 리그 선수들의 집단이주 현상은 대두되고 있 으며, 이에 대한 전반적인 이해와 학술적 논의가 필요한 시 점이다. 더욱이 본 연구자는 약 15 년의 축구선수 경력과 $\mathrm{K}$
리그 경험을 지니고 있다. 이러한 연구자의 배경은 $\mathrm{K}$ 리그에 대한 깊은 이해와 연구 참여자 선정에 큰 도움이 되기 때문에 본 연구 주제를 수행하는데 적합하다. 이에 본 연구는 관심 주제의 선행연구 부재와 연구 대상(사례)의 특수성을 고려하 여 질적 사례연구(Qualitative Case Study)를 실시하고자 한다.

서론을 다시 정리하면, 본 연구는 국내 프로축구선수들의 동남아시아로의 이주 요인을 탐색하고 이 현상에 대한 학술 적 및 실천적 논의를 제공하는 데 그 목적이 있다. 구체적으 로 국내 선수들이 동남아시아 국가로 이주하는 사회구조적 요인과 행위주체측면에서의 동기가 주요 관심이다. 그리고 본 연구를 통해 발견된 다양한 요인들로부터 한국의 스포츠 노동 이주에 대한 이론적 틀을 구축하고 더 나아가 이 현상에 대한 이해관계자(K리그 및 각 구단, 선수, 팬, 미디어 등) 측 면에서 실천적 논의를 제공하고자 한다. 끝으로 본 연구가 스포츠 노동 이주에 관한 스포츠사회학계의 지속적 관심과 현장에서의 제도적 개선으로 이어지길 기대해본다.

\section{연구방법}

질적 시례연구는 Yin(2014)이 주장한 '세 가지 전제’를 충 족할 때 유용한 연구 방법이다. 첫 번째로 연구 문제(질문)가 특 정 현상의 발생 요인과 그 과정을 규명하고자 할 때 적합하다. 본 연구는 국내 남성 축구선수들의 동남아시아 국가로의 이주 현상이 어떻게, 왜 발생했는지 살펴보는데 초점을 두고 있다.

다음으로 질적 사례연구는 연구자가 연구 대상(사례)을 통제할 수 없는 경우에 적합하다. 예를 들어, 본 연구 대상(사 례)인 '남성 축구선수들의 이주 현상' 을 연구자가 스스로 조 작할 수 없어야 함을 의미한다. 본 연구는 실제 이주 경험이 있는 선수들로부터 자료수집 및 분석이 이루어지며, 더욱이 연구자는 추후 이주 결정에도 영향을 미칠 수 없다.

마지막으로 연구 대상(사례)은 연구 시점과 관련성이 있 어야 한다. 이는 연구하고자 하는 특정 현상이 연구를 실시 하는 시점에도 유효해야 함을 의미한다. 본 연구에서 주목한 국내 축구선수들의 동남아시아 국가로의 이주 현상은 2014 년부터 활성화되어 현재도 진행형이다(Myung \& Lee, 2018). 이처럼 '질적 사례연구의 세 가지 전제(Yin, 2014)' 는 국내 프로축구선수들의 동남아시아 국가로의 이주 현상 과 본 연구 목적에 적합하다. 


\section{연구 참여자}

본 연구는 $\mathrm{K}$ 리그 구단에서 동남아시아리그로의 이적 경 험이 있는 국내 선수 및 에이전트를 연구 참여자로 선정하였 다. 선수 개인에게 제공 받을 수 있는 이주 동기와 전반적인 진술은 경험 중심적이기 때문에 연구의 객관타당성을 유지 하는데 제한이 있다. 이주 경험이 선수 개인적 측면에서만 해석 및 전달되기 때문이다. 이는 자기중심적 판단과 왜곡 된 정보가 분석 과정에 영향을 미칠 수 있다. 본 연구자는 이 런 문제를 사전에 인지하고 이를 위해 선수 대리인과 $\mathrm{K}$ 리그 관계자를 정보 제공자로 추가 선정하였다. 선수 대리인은 이적 과정에서 양 구단과 관계를 맺을 뿐만 아니라 모든 협 상 과정에 참여하고, $\mathrm{K}$ 리그 관계자는 국내 리그의 전반적인 상황을 잘 파악하고 있기 때문에 다양한 측면에서 자료를 수 집하는 데 도움이 된다.

연구 참여자 선정 방법은 눈덩이표집법을 이용하여 순차 적으로 연구 참여자를 소개받아 진행하였다. 눈덩이표집법 은 연구 문제에 부합한 참여자를 소개받아 나가는 방식으 로, 질적 연구에서 일반적으로 쓰이는 방법이다(Lee, 2013). 프로축구선수의 직업적 특성상 그들을 연구 참여자 로 선정하고 진실된 응답을 구하는 작업은 일반적으로 쉽지 않지만(Elliott, 2016; Magee \& Sugden, 2002; Roderick, 2013), -서론에서 밝혔듯이- 본 연구자의 프로 축구선수 경력은 참여자 모집에 큰 도움이 되었다.

눈덩이표집 시 적용한 연구 참여자의 선정 기준은 다음과 같다. 첫째, $\mathrm{K}$ 리그 구단에서 동남아시아 축구리그로의 공식 이적을 경험한 자이다. 이는 본 연구 목적을 달성하는데 핵 심 조건이며, $\mathrm{K}$ 리그를 경유하지 않고 대학이나 실업팀에서 곧바로 이주한 사례를 걸러내기 위함이다. 둘째, 대면 면담 여부이다. 본 연구의 특성상 연구 참여자들이 해외에 거주 하고 있기 때문에 대면 만남에 대한 사전 확인이 중요하다. 연구자는 참여자에게 비시즌 기간 중 국내 방문 계획을 사전 에 질의한 후 대면 면담의 가능성을 확인하였다. 셋째, '적극 적인' 연구 참여 동의이다. 질적 연구에서 참여자의 태도와 마음가짐은 자료 수집의 결정적인 부분을 차지한다. 이에 연구자는 참여자가 자신의 이주 경험을 솔직하고 풍부하게 진술해줄 수 있는지를 추가 선정 기준으로 고려하였다.

위 선정 기준을 바탕으로 9명의 선수(태국 4명, 말레이 시아 3명, 베트남 2명)와 이들의 이주 과정에 관여한 4 명의 에이전트, 2 명의 $\mathrm{K}$ 리그 관계자를 연구 참여자로 선정하였
다. 참여자들의 나이, 이주 국가(리그), 포지션, 신분(역할) 등 인구통계학적 특성은 다음 〈Table 1)과 같다.

Table 1. Personal characteristic of the participants

\begin{tabular}{|c|c|c|c|c|c|}
\hline No. & Name* & Age & League & Position** & Role \\
\hline 1 & $\mathrm{KDF}$ & 26 & Thailand & FW & \multirow{9}{*}{ Footballer } \\
\hline 2 & ASD & 28 & Thailand & FW & \\
\hline 3 & GFD & 30 & Thailand & DF & \\
\hline 4 & FER & 33 & Thailand & DF & \\
\hline 5 & DDF & 28 & Malaysia & FW & \\
\hline 6 & AAS & 33 & Malaysia & MF & \\
\hline 7 & DFS & 34 & Malaysia & DF & \\
\hline 8 & HTH & 29 & Vietnam & FW & \\
\hline 9 & FVD & 30 & Vietnam & FW & \\
\hline 10 & МJH & 34 & - & 1,6 & \multirow{4}{*}{ Agent } \\
\hline 11 & BNV & 44 & - & 2,4 & \\
\hline 12 & CVD & 48 & - & $3,8,9$ & \\
\hline 13 & ZSA & 50 & - & 5,7 & \\
\hline 14 & ASD & 36 & - & - & \multirow{2}{*}{$\begin{array}{c}\text { League } \\
\text { staff }\end{array}$} \\
\hline 15 & PKG & 40 & - & - & \\
\hline
\end{tabular}

*Anonymity was used.

**Agents have contracted with footballers of each number.

\section{자료수집 및 분석}

본 연구는 Yin(2014)이 제안한 질적 사례연구의 자료 수 집 자료원 중 심층면담과 문헌자료를 주요 분석 자료로 활용 하였으며, 개별 서술형 질문지와 연구자의 반성일지를 추가 적으로 실시하였다. 구체적인 자료 수집 및 분석 방법은 다 음과 같다.

첫째, 연구 참여자들을 대상으로 심층면담을 실시하였다. 심층면담은 참여자들이 비시즌 기간 중 국내에 체류하는 시 기에 이루어졌으며, 개인별 1-2회(최소 40분에서 최대 90 분) 진행하였다. 면담 장소는 주로 식당과 카페에서 이루어졌 으며, 간혹 선수의 자택에서 진행하기도 했다. 1 차 면담은 비 구조화된 면담으로 진행하였다. 연구 참여자들의 삶과 이주 에 관한 전반적인 내용을 자유로운 대화 형식으로 주고받았 다. 2 차 면담은 반구조화된 면담으로 1 차 면담의 내용을 바 탕으로 고안한 개별적 질문과 연구 문제에 따른 공통적 질문 
그리고 자유 토론으로 진행하였다. 주로 개별 면담으로 진행 하였으며 경우에 따라 선수와 담당 에이전트가 함께 참여하기 도 했다. 면담 녹음 파일은 면담 당일 전사하는 것을 원칙으로 하였다. 면담 질문에 대한 내용은 다음 〈Table 2〉와 같다.

Table 2. In-depth interview questions

\begin{tabular}{|c|c|}
\hline Items & Questions \\
\hline $\begin{array}{l}\text { First interview } \\
\text { (Unstructured } \\
\text { interview) }\end{array}$ & $\begin{array}{l}\text { - Self introduction } \\
\text { - Career as a footballer } \\
\text { - Background of migration } \\
\text { - Process of migration }\end{array}$ \\
\hline $\begin{array}{c}\text { Second interview } \\
\text { (Semi-structured } \\
\text { interview) }\end{array}$ & $\begin{array}{l}\text { - Migration motives (e.g. Career, income, } \\
\text { self esteem, treatment, living, education, } \\
\text { retirement, family, co-players, agents, } \\
\text { coaches, etc.) } \\
\text { - Social structural factors of migration } \\
\text { (International football trend, leagues, } \\
\text { clubs, policy, economy, culture, } \\
\text { geography, climate, media, etc.) } \\
\text { - Plan for career as a footballer }\end{array}$ \\
\hline
\end{tabular}

둘째, 국내 스포츠 선수들의 이주와 관련된 문헌을 수집 하였다. 선행연구뿐만 아니라 언론 매체의 보도 자료를 적 극 활용하였다. 보도 자료는 스포츠 전문 매체로부터 연구 참여자를 포함한 국내 프로축구선수들의 동남아시아로의 이적을 다룬 뉴스 기사를 수집 및 활용하였다. 스포츠 노동 이주 관련 선행연구와 국내 선수들의 이주 관련 보도 자료는 심층면담을 분석하는 과정에서 보조 자료로 사용하였다. 문 헌 검토를 통해 심층면담 내용에 관한 정확한 출처나 추가 정보를 얻을 수 있고, 자료의 다각적 검토가 가능하기 때문 에 자료 분석의 정확성과 안정성을 확보할 수 있었다.

셋째, 연구 참여자들과의 2차 심층면담 종료 후 개별 서 술형 질문지를 개발하여 SNS로 배포 및 수집하였다. 개별 서술형 질문지는 심층면담 이후 추가적인 질문이 필요한 경 우에 실시하였다. 예를 들면, 연구자가 특정 참여자의 진술 내용과 의도를 명확히 이해하지 못한 경우, 결과 도출에 영 향을 미치는 내용을 해당 참여자에게 재확인하는 경우, 특 정 진술 내용에 대한 배경과 이유를 추가로 수집하는 경우이 다. 이는 즉각적인 문답 형식으로 이뤼지는 인터뷰 방식과 달리, 참여자들이 개인 공간에서 시간적 여유를 가지고 응 답할 수 있다는 장점이 있다.
마지막으로 연구 설계부터 연구 종료 시까지 연구일지를 작성하였다. 특히, 연구 참여자들과의 심층면담 후 느낀 점 과 개인감정을 솔직하게 기술하였다. 또한, 자료 분석 및 결 과 도출 과정에서 연구자의 편협적인 관점을 주의하고 판단 오류를 최소화하기 위해 연구자 성찰에도 적극 활용하였다.

본 연구는 주제 분석(thematic analysis)을 통해 $\mathrm{K}$ 리그 선수들의 동남아시아로의 이주 요인에 대한 공통 주제 및 그 의미를 밝히는데 초점을 두었다. 주제 분석은 귀납적 접근 을 통해 비정형화된 수집 자료로부터 공통 주제를 범주화하 는데 유용하다(Hatch, 2002). 본 연구는 Braun \& Clarke(2006)가 제시한 주제 분석의 6단계(원자료, 초기부 호생성, 주제생성 및 분류, 주제점검 및 평가, 주제명명 및 정의, 결과보고서)를 엄격하게 준수하였다.

\section{연구의 진실성과 윤리성}

본 연구는 연구 진실성을 확보하기 위해 Lincoln \& $\mathrm{Guba}(1985)$ 의 질적 연구의 평가 기준(사실적 가치, 적용성, 일관성, 중립성)과 Patton(2002)의 다각적 자료 수집 기법 (multiple data collection technique)을 준수하였다. 구 체적으로 동일 질문에 대한 연구 참여자의 답변의 일관성, 기 존 이론 및 관련 문헌의 체계적 고찰, 동료 검증, 결과에 대한 연구 참여자의 재검토를 실시하였다. 또한, 심층면담, 개별 서술형 질문지, 관련 문헌, 연구자 반성일지 등 다각적 자료 수집 및 분석을 통해 연구자의 분석 오류를 최소화하였다.

본 연구는 연구 계획 단계에서 $\mathrm{A}$ 대학 생명윤리심의위원 회(IRB)로부터 연구 승인을 얻었다. 모든 연구 참여자들은 $\mathrm{IRB}$ 로부터 승인받은 연구 설명문을 충분히 검토한 후 연구 참여 동의서에 서명하였다. 수집된 모든 자료는 문서화하여 3 년 이상 보관할 것이며, 본 연구 이외에 다른 목적으로 사용 및 유출하지 않을 것을 약속한다.

\section{연구결과}

\section{새로운 시장과 기회의 땅: “개척을 위해서"}

“솔직히 말해서 과거에는 한국선수들이 동남아리그는 안 가려고 했지. 그런데 거기도 지금 축구 시장이 발전하고 있고, $\mathrm{K}$ 리그보다 연봉도 더 
많이받을수있고경기출전시간이보장되니까. 경쟁에서살아남지못 한 젊은 선수들이 가는 곳이기도 하지만 은퇴를 앞두고 가는 선수들도 많지." - 선수 6

“한국에서는 기회를 전혀 못 받았어요. 제가 뛸 수 있는 팀을 찾아서 떠난 게 첫 번째였고요. 그곳이 동남아 리그가 적합하다고 생각을 했어요." - 선수 2

“인천에서 출전 기회를 많이 못 받았지. 나를 조금 더 대우해 줄 수 있는 곳을 찾다가 태국에 대해 알게 되었고 이적을 결심하게 되었 지." - 선수 4

중국 및 중동 국가로 이주하는 국내 프로축구선수들과 달 리 동남아시아 국가로 이주하는 선수들은 주로 국가대표팀 경험이 없는 선수들이다. 대부분 $\mathrm{K}$ 리그의 평균 연봉에 못 미 치는 선수들이 동남아시아 국가로의 이주를 결심하고 있다. 일부 사례의 경우에는 $\mathrm{K}$ 리그에서 경기 출전 기회를 보장받 지 못하거나 소속팀으로부터 일방적인 계약 해지를 당한 선 수들이 이주를 선택하고 있다. 다시 말해, $\mathrm{K}$ 리그의 고연봉 선수들은 중국과 중동 국가로, 저연봉 선수들은 동남아시아 국가로의 연쇄이동이 ' $\mathrm{K}$ 리그 엑소더스(한국 축구선수들의 동시다발적 해외 이주)' 현상의 특징이라고 할 수 있다 (Myung \& Won, 2019).

$\mathrm{K}$ 리그 선수들이 동남아시아를 기회의 땅으로 주목하고 있는 이유는 동남아시아 축구 시장의 성장과 잠재가능성이 다. 특히, 태국은 프로스포츠선수의 권리를 보호하는 'Professional Sport Act'을 제정한 동남아시아 최초의 국 가로서 주변국보다 축구 산업의 상당한 진전을 이루었다 (Brill \& Nin Siriwat, 2016). 대표적인 예로, 리그의 평균 선수 연봉과 중계권료 가치가 이를 방증한다.

독일의 축구 전문 웹사이트 Transfermarkt에 따르면, 2016년 기준 태국 프리미어리그(이하 TPL) 등록 선수의 최 고 연봉은 약 17 억 원(약 150 만 달러)으로 같은 기간 국내 프 로축구리그의 14 억 원보다 높은 수준이다. 프로스포츠리그 의 가치와 수요를 판단하는 데 유용한 지표인 중계권료 역시 동남아시아 축구시장의 성장을 반영한다. TPL의 3 년간 중 계권료는 18억 바트(약 600억 원)로 2014년 기준 K리그 중 계권료(약 65억 원)의 약 3배 이상이다(Kim, 2014, Apr 28). 한편 말레이시아 슈퍼리그(MSL)는 글로벌 스포츠 중계 권 에이전시인 MP\&Silva와 15년간 약 3,300억 원 수준의 중계권 계약을 체결하기도 했다(Lee, 2015, Feb 4).
이렇듯 동남아시아 축구 시장의 성장은 $\mathrm{K}$ 리그 선수들뿐 만 아니라 세계 각국의 축구선수들에게 새로운 시장으로서 그 가치가 상승하고 있다. 2012년부터 태국 프로축구리그에 등록된 외국인 선수 수는 눈에 띄게 급증하였으며, 2015년 시즌에는 31 개 국가에서 총 116 명이 등록된 것으로 나타났 다(Siriwat \& Brill, 2015).

Siriwat \& Brill(2015)은 그동안 관광 국가로 알려진 태 국은 최근에는 다수의 축구 재능들이 이주하는 국가로 변화 하고 있다고 하였다. 그들은 태국으로 이주한 외국인 선수들 의 추진-유인 요인(push and pull factors)을 연구한 결과, 자국 리그의 열악한 재정 상태, 경기 출전 기회의 감소, 과거 팀으로부터의 방출 또는 재취업 실패 등이 추진 요인으로 나 타났다. 반면에 더 높은 임금 조건, (외국인에게)따뜻한 환 경, 저렴한 생활비 및 복리후생, 가족과의 동행, 에이전트와 선수 간의 네트워크 활성화, 편리하고 안전한 송금 시스템 등이 유인 요인으로 나타났다.

이처럼 동남아시아 축구리그 특히, 태국축구리그로 이주 한 외국인 선수들의 추진 요인은 본 연구 참여자들로부터 발 견된 이주 요인과도 밀접한 관계가 있음을 확인할 수 있다. 주로 자국 리그에서 취업 및 재취업의 기회를 보장받지 못한 선수들이 새로운 고용 기회를 찾아 동남아시아로 이동하는 것이 공통점이다. 재정적 및 환경적 측면에서도 이주 전 국 가와 비교했을 때 만족스러운 수준인 것으로 나타났다. 한편 으로 이런 현상은 그동안 세계 축구에서 주변부에 위치했던 동남아시아 축구시장의 비약적 발전을 의미한다.

\section{$\mathrm{K}$ 리그 재정 악화와 선수단 규모 감축: “생존을 위해서”}

"K리그에서 평균 연봉을 받고 경기도 잘 뛰었던 선수가 FA가 됐는 데갈곳이 없어. 그러면 태국으로 테스트라도 보러가야 돼. 엄청웃 긴 상황인거야. 근데 그렇게 가서 낮은 연봉을 받는 경우가 대부분 이야. 그 선수들은 돈을 벌려고 가는 게 아니라 생존을 위해서 가는 거야." - 에이전트 3

"최근에 K리그 구단들은 저비용 고효율을 주장하고 저렴하고 어린 선수를 선호하니까 나이 있는 선수들은 갈 곳이 없어. 직장을 잃어 버린 거야. 20대 후반에 은퇴를 강요당하는 것처럼 되고 계약할 팀 도 없고. 그래서 자신의 가치를 보상받을 수 있는 곳이면 어디든 가 겠다는 거야." - 에이전트 2

"나는 정말 경기를 뛰고 싶었어. 가장 중요한 건 축구를 하고 싶었 어. 내가 오랜 시간동안 축구를 했는데 이렇게 하찮은 대우를 받을 
바에는 외국(동남아시아) 쪽으로 선택을 하게 된 거지." - 선수 4

본 연구 참여자들이 선수로서 수명을 연장하기 위해, 즉 경력 유지를 위해서도 이주를 선택한 것으로 확인됐다. $\mathrm{K}$ 리 그 구단으로부터 방출을 당한 선수, 재계약에 실패한 선수, 은퇴를 앞둔 30 대 중후반 선수들이 선수로서의 삶을 유지하 기 위해 이주를 선택하였다. 그리고 그 중심에는 $\mathrm{K}$ 리그 구단 들의 재정 악화와 그에 따른 선수단 규모 감축이 큰 영향을 미치고 있다.

1983 년, $\mathrm{K}$ 리그는 각 구단의 경영 전반을 모기업에 의존 하는 구조적 문제를 가지고 출범하였다. 출범 이후 각 구단 이 내놓는 수익 모델은 큰 성과를 내지 못하고 있으며, 모기 업에 대한 의존도는 더욱 심화되고 있다. 그 결과, $\mathrm{K}$ 리그 구 단들은 매년 적자 운영을 반복하고 있다(Kim \& Park, 2014). 그럼에도 불구하고 $\mathrm{K}$ 리그의 양적 성장 및 프로스포 츠를 통한 시민들의 통합이라는 명목 아래 창단되었던 시 도민구단 역시 지방자치단체의 예산 낭비라는 불명예를 안 고 있다. $\mathrm{K}$ 리그 시·도민 프로축구구단의 경영환경을 연구한 $\operatorname{Kim}(2013)$ 은 "매년 유동성 악화, 레버리지(leverage)비율 증가, 수익성 감소가 심화되고 있다”고 보고하였다. 이처럼 그동안 지속되어온 $\mathrm{K}$ 리그의 적자 운영 구조는 최근 모기업 들의 재정 악화와 맞물리면서 기업 구단들의 운영 예산 감축 을 피할 수 없게 되었다.

$\mathrm{K}$ 리그의 대표적인 클럽이자 삼성전자를 모기업으로 두었 던 수원 삼성, 포스코를 모기업으로 두고 있는 전남 드래곤 즈와 포항 스틸러스의 사례를 통해 $\mathrm{K}$ 리그 구단들의 재정난 을 확인할 수 있다. 과거 수원은 구단 운영 예산으로 연간 300 억 원 이상을 지출하여 국내외 스타 선수들을 영입하면 서 '레알 수원(레알 마드리드와 수원의 합성어)' 으로도 불린 적이 있었다. 그러나 2014년부터 계열사인 제일기획에 편입 된 이후 연간 예산이 200억 원 이하인 것으로 추정되고 있으 며, 매년 선수단 인건비 감축에 나서고 있다(Lee, 2015, Dec 15). 실제로 한국프로축구연맹에 따르면 수원의 선수 연봉 총액은 2014년 98억 원에서 2015년 87억 원, 2016년 76억 원으로 매년 큰 폭으로 감소하는 추세이다. 이뿐만 아 니라 최근 세계 경제 침체로 인한 포스코의 실적 악화도 한국 축구계에 큰 영향을 주고 있다. 한국 재계 순위 6위인 포스코 는 1968년 창립 이후 처음으로 적자를 기록하였으며, 구단 운영비용을 모기업에 의존하는 전남과 포항은 운영 예산 감 축의 고통을 분담하고 있다(Do, 2016, Jan 21).
이처럼 구단 수익의 대부분을 모기업에 의존하는 비정상 적 구조는 모기업의 재정 악화에 따른 운영 예산 축소를 야기 하였다. 그중에서도 선수들의 임금은 매년 눈에 띄게 감소하 고 있으며, 인건비 감소는 선수단 규모의 축소로 이어져 $\mathrm{K}$ 리 그 내 실업자와 국제 이주자 특히, 동남아시아로의 스포츠 노동 이주자들을 양산하는데 기여하고 있다.

\section{FA보상금제도: “계약이 끝나도 끝난 게 아니다"}

한국프로축구연맹의 규정집 제2장 선수, 제 16 조 FA선수 자격 취득, 제6항에 따르면 “소속 클럽과 계약 기간이 만료 된 선수는 계약 기간 종료 후 보상금제도를 적용한다" 고 명 시되어 있다. 여기서 보상금제도란 $\mathrm{K}$ 리그에만 존재하는 로 컬룰로서 FA자격을 취득한 선수가 타 팀으로 이적시 이적 직 전 연도 기본급 연액의 $100 \%$ (최대 3 억 원)를 양수 클럽이 원 소속 클럽에 지급해야 하는 제도이다. 즉 소속팀과의 계약이 만료되었음에도 불구하고 $\mathrm{K}$ 리그의 타 팀으로 이적 시 이적 료 아닌 이적료가 발생하는 것이다(Myung \& Park, 2020). 물론 $\mathrm{K}$ 리그에만 있는 로컬룰이기 때문에 해외 구단으로의 이주 시에는 적용되지 않는다.

이러한 $\mathrm{K}$ 리그만의 독특한 규정은 본 연구 참여자들의 이 주 사례에서 구조적인 요인으로 발견되었다. 이 규정으로부 터 직접적인 영향을 받는 선수들은 주로 $\mathrm{K}$ 리그 평균 연봉을 받는 20 대 중후반 또는 30 대 선수들이다. 자의든 타의든 소 속구단과의 재계약 실패로 인해 FA자격을 얻은 선수들은 다 른 팀을 모색해야 하지만 이들의 원소속 클럽에게 보상금을 지급하고 영입할 구단을 찾기가 쉽지 않다. 결국 $\mathrm{K}$ 리그 이적 시장 종료일까지 소속팀을 찾지 못한 선수들이 리그의 경쟁 력 및 연봉과 관계없이 해외 구단으로 눈을 돌리고 있다. 실 업 상태보다는 당장 선수 생활을 유지할 수 있는 구단을 찾아 떠나는 것이다. 보상금제도로 인해 FA선수임에도 불구하고 특정 선수를 영입하는데 드는 비용은 실제 연봉의 두 배이기 때문에 재정 상태가 좋지 않은 $\mathrm{K}$ 리그 구단에게는 부담이 아 닐 수 없다. 실제로 연구 참여자들의 진술에 의하면 최근 동 남아시아로의 이주에서 이러한 이주 패턴이 자주 발생하고 있었다.

\footnotetext{
"선수가 FA가 됐는데 한국 K리그 규정이 다른 팀으로 이적하려고 하면 보상금제도라는 게 있어요. 다른 나라에는 이런 게 어디 있겠 어요. 이세상 어디에도 없고 대한민국에만 있어요. FA로 나와도 이 적료가 있는 셈이죠. (중략) $A$ 선수도 B팀에서 1억 3천 받는 선수인
} 
데 나한테 연락이 왔어요. 한국에서 보상금제도 때문에 갈 팀이 없 대요. 그래서 저보고 외국으로 팀을 알아봐달라고 해서." - 에이전 트 1

“보상금 제도가 $K$ 리그 팀 간 이적을 많이 힘들 게 하고 있어요. (중 략) 보상금 때문에 K리그 클럽으로 못 가니까 동남아라도 보내달라 는 선수들이 많이 있어요. 해외에는 이런 규정이 없어요. FA는 FA 에요. 계약 기간 끝나면 끝이에요." - 에이전트 4

"FA가FA가 아니야. 어떻게 보면 이적료가 있는 거야. FA인데 K리 그 클럽에서 콜이 없어. 보상금내고 영입하는 것보다 더 저렴한 연 봉으로 어린 선수 쓰는 거야. 정말 선수 죽이는 제도야. 그러다 보니 까 선수들도 자존심 상하고 화도 나고 동남아로 가는 경우도 많이 있지." - 선수 9

이처럼 $\mathrm{K}$ 리그의 보상금제도는 $\mathrm{K}$ 리그 간 이적에 상당한 제약으로 기능하고 있으며 이는 $\mathrm{K}$ 리그 내 이적 시장의 침체 를 야기하였다. 특히, $\mathrm{K}$ 리그 선수 평균 연봉을 웃도는 20 대 중후반 또는 30 대 선수들은 이 제도로부터 가장 큰 영향을 받고 있다. 재정적으로 어려움을 겪고 있는 $\mathrm{K}$ 리그 구단 입장 에서 보상금(이적료)을 지불하고 이들을 영입하는 것보다 낮 은 비용(연봉)으로 영입이 가능한 신인급 선수들을 선호하게 된 것이다. 결국 $\mathrm{K}$ 리그에서 일자리를 잃은 중견 선수들은 보 상금제도라는 로컬룰을 벗어나 동남아시아 국가로의 이주를 선택하고 있으며, 이런 형태의 이주 패턴은 $\mathrm{K}$ 리그 선수들의 동남아 이주 현상의 구조적 원인 중 하나로 발견되었다.

\section{한국 스포츠계 위계적 집단문화: “자유를 찾아서”}

국가 및 조직 문화 연구에 저명한 Hofstede(1984:151) 는 "동양의 집단주의 문화는 서구의 개인주의 문화와 함께 큰 사상적 척도를 이루고 있다"고 하였다. 개인의 자기효용 성(self-efficiency) 개발을 강조하는 서양의 개인주의와 달 리, 동양의 집단주의는 개인보다는 집단의 이익과 목표에 관 심을 가지고 전체적인 화합과 조화를 강조한다(Earley, 1989). 이러한 집단주의 문화는 유교사상과 결부되어 한국 의 가정, 학교, 직장, 종교단체 등과 같은 사회 구조 내에서 더욱 극명하게 나타난다. So(2010:413)는 "동양의 집단주 의 문화와 한국의 유교사상은 한국 사회에서 개인들의 자기 표현과 의사전달을 집단 속에 함몰시켜 왔다"고 언급하였다.

다시 말해, 예의를 강조하는 유교사상은 현대 한국 사회 의 엄격한 위계질서 아래 타인(특히, 부모, 지도자 및 선배,
직장 상사와 같은 수직적 관계)과 집단에 무조건적으로 순응 하는 사회 체계에 기여한 것이다(Kim, 2000; So, 2010).

이처럼 한국 사회에 만연한 집단주의 문화와 유교사상은 국내 학원스포츠와 프로스포츠 영역에서도 전통적으로 깊게 뿌리내려왔으며, 이러한 위계적 집단문화로부터 적지 않은 사회적 문제들이 발생해왔다. 특히, 학원스포츠부터 프로스 포츠까지 의무적으로 실시되고 있는 합숙 제도는 많은 문제 들의 근원으로 꼽히고 있다. 학원 스포츠 내 합숙소의 폐쇄 적 구조로 인한 (성)폭력 문제(Heo et al., 2008; Kim, 2010; Lee \& Shin, 2014), 구속되는 삶, 억제되는 삶, 외로 운 삶(Park et al., 2012)은 여러 선행연구에서 보고된 바 있 다. Jung(2016, Nov 1)에 의하면, 한국 프로야구 A감독이 선수들의 외출 금지와 외박 월 1 회 제한 등 합숙소 규율을 강 제하면서 사생활 및 인권침해가 드러나기도 했다. 대학 여성 축구팀의 연중 합숙훈련 및 군대와 유사한 지배와 통제 (Kwon \& Lim, 2012), K리그 선수들의 합숙훈련으로 인한 제한된 사생활(Myung, Won, \& Koo, 2015)도 한국 스포 츠계의 위계적 집단 문화를 반영하고 있다.

본 연구 참여자들의 진술 내용에서도 $\mathrm{K}$ 리그의 위계적 집 단문화로부터 벗어나고자 해외 이주를 선택하는 사례가 어렵 지 않게 발견되었다. 구체적으로 지도자와의 의사소통 단절, 합숙으로 인해 단절된 사생활, 경기결과에 따른 보복 행위, 구 단 내 파벌, 선배 선수들의 억압 등이 빈번하게 도출되었다.

"한국에서는 (축구 외에도)신경 쓸 문제가 너무 많아요. 지도자 눈 치도 봐야 되고 선배들한테도 깍듯이 잘해야 되고 말도 잘 들어야 되고 단체로 해야 되는 것들이 너무 많아요. 항상 단체로 움직여야 되고 밥도 다 같이 먹어야 되고. 외국은 위계적인 분위기가 없어서 자유로워요. 한국에서는 지도자들이랑 선배들이랑 트러블도 많았 어요." - 선수 2

"한국에서는 합숙을 했었어. 심지어 유부남도 합숙하는 경우가 있 어. 예를 들어 경기를 지면 그날부터 보복이 시작돼. 외박을 취소시 키거나 훈련 강도를 높이거나. 여기(태국)는 합숙도 안하고 그냥 훈 련 시간에 모여서 훈련하고 끝나면 퇴근하고." - 선수 7

"선수들이 나가려고 하는 이유가 금전적인 부분이 물론 크지만 나 는 환경이나 문화적인 부분도 큰 거 같아. (중략) 우리나라 같은 경 우에는 감독, 코치 눈치도 보지만 선후배 관계도 폐쇄되어 있고 쉽 지 않아. 실제로 지금 $\mathrm{K}$ 리그에서 뛰고 있는 친구들한테 물어보면그 런 불만들이 반 이상이야. 돈도 돈이지만 한 번 외국에 나갔던 선수 들은 그 자유로움을 알기 때문에 계속 나가려고 하지. 솔직히 운동 
도 너무 강압적이야. 한국이 아직까지는 유교사상도 있고 합숙도 해 야 되고 자유롭지 못하잔아. (중략) 그게 바뀌지 않으면 선수들은 계 속 외국으로 나가려고 할 거야. 나는 그렇게 생각해." - 선수 1

이처럼 위의 진술 내용과 몇몇 선행연구들을 통해 국내 학원스포츠와 프로스포츠(특히, 축구와 같은 단체종목) 영 역에서 위계적 집단문화는 더욱 분명하게 나타나고 있다. 또한, 위계적인 스포츠 집단문화로부터 야기된 각종 사회적 문제들도 언론보도를 통해 어렵지 않게 접할 수 있었다.

그러나 1980년대 대한민국의 정치적 민주화와 2000년 대 국가인권위원회 설립 등은 한국 사회의 보편적 가치로서 인권 사상이 발전하는 계기를 맞이하였다(Choi, 2004). 이 는 학원스포츠와 관련된 각종 인권 문제가 법적으로 보호받 는 데에도 상당한 기여를 하였다. 실제로 합숙훈련 규제, 최 저학력제도 도입, 주말리그제도 도입 등이 학생선수들의 인 권과 학습권 보장을 위해 범정부 차원에서 실시된 것이다.

이와 함께 최근 스포츠 영역에서의 선진 문물(외국인 지 도자 및 선수, 운영체계) 수용과 SNS의 발달은 더 이상 선수 들이 집단 내 수동적 객체가 아닌 능동적 주체로서 그 인식 이 변화하였다. 그러나 본 연구에서도 재확인했듯이 $\mathrm{K}$ 리그 내에 잔존하는 위계적 집단문화는 선수들로 하여금 기피의 대상이 되고 있다. 보다 자유로운 운동장에서 훈련하기 위 해, 보다 자유로운 환경에서 생활하기 위해 연구 참여자들 은 해외로의 이주를 선택하고 있다.

\section{논 의}

이번 장에서는 앞서 살펴본 네 가지 결과를 바탕으로 학술 적 및 실천적 논의를 제공하고자 한다. 구체적으로 〈새로운 시장과 기회의 땅: 개척을 위해서〉, 〈K리그 재정 악화와 선 수단 규모 감축: 생존을 위해서〉는 추진-유인 이론을 차용하 여 국내 스포츠 노동 이주와 관련된 이론적 논의를 확장하였 다. 특히, 선행연구에서 주목하지 못했던 비주류선수들의 이 주, 즉 비자발적 이주 사례에 대한 새로운 이주론을 적용하 였다. 다음으로 〈FA보상금제도: 계약이 끝나도 끝난 게 아니 다〉, 〈한국 스포츠계 위계적 집단문화: 자유를 찾아서〉는 국 내 스포츠계의 문화와 제도에 초점을 두고 현장에 의미 있는 논의를 제공하였다. 이러한 실천적 논의는 스포츠 노동 이주 가 스포츠사회학 연구 주제로서 다양한 사회 현상을 반영하
고 있음을 보여준다.

\section{스포츠 노동 이주와 추진-유인 이론}

그동안 축적되어온 스포츠 노동 이주에 관한 학술적 논의 는 크게 두 가지 관점으로 구분할 수 있다. 첫째, 운동선수들 의 이주를 자본주의 체계 아래 '착취’로 바라본 마르크스주 의적 구조주의와 둘째, 글로벌 아웃소싱 개념을 활용하여 이 주 국가 간 '이해관계'에 주목한 것이 그것이다(Baur \& Lehmann, 2007; Darby, 2007a, 2007b; Darby et al., 2007; Lee, 2010). 그러나 이들 관점은 자본주의 구조와 경 제학적 측면에서 스포츠 노동 이주를 설명하기 때문에 비자 발적 이주와 같은 특수한 또는 소수의 사례를 포괄하지 못하 는 한계점을 지니고 있다. 여기서 언급한 비자발적 이주란 소속팀으로부터 일방적 계약해지나 재계약 실패를 경험한 선수가 국내 다른 구단으로의 이적에 실패하여 해외로 떠난 경우를 의미한다. 이때 선수와 그 에이전트는 해외 구단의 영입 제안보다는 일련의 테스트 과정을 거쳐 이적을 추진하 는 것이 일반적이다.

본 연구는 연구 참여자들의 이주 요인으로부터 이들의 이 주 형태를 비자발적 이주로 규정하였다. 주로 $\mathrm{K}$ 리그 구단으 로부터 방출당한 선수, FA보상금제도로 인해 (재)계약에 실 패한 선수, 상대적으로 연령이 높은 선수들이 그 대상이었으 며, 이들의 주요 목적지는 동남아시아 축구리그이다.

Myung \& Lee(2018) 역시 국내 프로축구선수들의 해외 이주에 관한 뉴스 프레임 분석을 통해 국가별 및 연도별 지배 적 프레임의 차이를 확인하였는데, 동남아시아로의 이주는 '대안적 프레임'이 지배적이었다. 여기서 대안적 프레임은 회복, 기회, 전환점, 은퇴준비, 경력유지 등의 키워드로 구성 된다. 이처럼 비자발적 이주 형태는 보다 좋은 조건 아래 이 주를 선택했던 기존 축구선수들의 사례들(Darby, 2007a; Darby et al, 2007; Elliott, 2013; 2016; Magee \& Sugden, 2002; Molnar, 2006)과는 다른 양상임을 보여준 다. 이는 그동안 스포츠 노동 이주 연구가 자발적 이주 사례 에 주목한 반면, 비자발적 이주에 관한 학술적 논의에는 등 한시한 것으로 풀이된다.

이에 본 연구에서는 K리그 선수들의 비자발적 이주를 이 해하기 위한 대안적 이론으로 추진-유인 이론(push-pull theory)을 차용하였다. Ravenstein(1889)의 '이주 법칙 (laws of migration)'에 의해 개발된 추진-유인 이론은 노 
동의 공급과 수요 과정에 보다 초점을 두고 있다. 여기서 추 진 요인이란 특정 이주 사례가 발생한 출발 국가(또는 지역) 에 존재하며, 유인 요인은 도착 국가에서 발견할 수 있다 (Kline, 2003). 이주를 설명하는 데 있어 경제적인 요인이 지배적일지라도 저개발 지역에서의 인구(또는 빈곤) 증가가 개발 국가의 높은 임금만큼이나 중요하다는 것이 Ravenstein의 추진-유인 모델의 핵심이다. 이에 대한 근거 로 Ravenstein(1889)은 잉글랜드 농촌 지역의 인구 증가와 도시 이주의 관계를 검증하였다. 결국 "노동의 공급과 수요 의 불균형'이 지역 간 추진-유인 작용을 통해 노동 이주를 초 래한다는 것이다.

상업화된 프로스포츠 시장은 이러한 노동 시장의 공급과 수요 과정 그리고 노동력 이동을 명확하게 보여준다. 대표적 으로 '스포츠 노동의 과잉 생산(Miller et al., 2003)'이 그 예이다. Elliott \& Maguire(2008)에 따르면, 미국 프로농구 선수의 노동력 과잉 생산과 공급이 국내 선수들의 해외 이주 를 촉진한다고 하면서, 그 이론적 근거로 추진-유인 과정을 제시하였다. 마찬가지로 다수의 브라질 축구선수들이 다른 국가에서 활동하고 있는 사실 또한 국제 노동 시장에서의 공 급과 수요 과정에 의해 설명할 수 있다(Lee, 2010). 또한, 한 국 프로농구시장도 파워 포워드나 센터의 노동력 수요가 높 은 반면, 공급이 제한적인 대표적인 사례이다(Lee, 2010).

Magee \& Sugden(2002)는 축구선수들의 이주가 강제 적인 또는 선택에 의해서가 아닌 상황에서도 일어난다고 언 급하였다. 유럽 국가에서 미국으로 이주하는 많은 축구선수 들이 대부분 이 경우에 해당한다(Elliott \& Harris, 2011). 특정 스포츠에서는 최고의 실력을 가진 선수만이 고용 및 경 기 출전 기회를 획득할 수 있으며, 나머지 선수들은 해외 국 가에서 그 기회를 찾아야 한다(Elliott \& Harris, 2011). 일 부 선수들에게 해외 이주는 그들의 선수 생활을 연장할 수 있 는 유일한 수단이기 때문이다(Roderick, 2013). 여기서 언 급한 해외 리그는 자국보다 시장 가치와 경쟁력이 낮은 국가 의 리그를 의미한다. 이러한 이주 형태는 선수들이 자발적인 선택보다는 프로스포츠선수로서 경력을 유지하기 위해 필연 적으로 해외 이주를 선택할 수밖에 없음을 보여준다.

추진-유인 이론의 관점에서 본 연구 참여자들의 이주 사 례는 한국 프로축구시장에 존재하는 공급과 수요의 불균형 으로부터 그 설명이 가능하다. 2017년 기준, 대한체육회 스 포츠지원포털(sportsg1.or.kr)에 따르면, 국내 엘리트 스포 츠 인구(공급)와 프로스포츠 구단(수요)의 극심한 불균형을
확인할 수 있다. 한국의 4대 프로스포츠 리그인 축구, 야구, 농구, 배구 종목의 잠재적인 채용 인원(초·중등, 대학 학생선 수)을 비교해보면, 축구 24,535 명, 야구 8,952 명, 배구 1,656 명, 농구 1,544 명 순이다. 반면에 이들을 수용할 수 있 는 프로스포츠 구단(1부 리그 기준)은 축구 12 개, 야구 10 개, 농구 10 개, 배구 7 개이다(각 리그 홈페이지 참고). 이 자 료는 $\mathrm{K}$ 리그의 잠재적 고용 인원이 $\mathrm{KBL}, \mathrm{KOVO}, \mathrm{KBO}$ 보다 약 3 배에서 15 배 많음에도 불구하고 수용 가능한 구단은 그 에 상응하지 못함을 보여준다.

여기에 동남아시아 축구시장은 국내에서 일자리를 잃은 축구선수들에게 새로운 기회를 제공해주고 있다. 앞서 결과 에서 확인했듯이, 그동안 국제 축구계에서 주변부에 위치했 던 동남아시아 축구리그는 비약적 성장은 물론 일부 영역에 서 한국 $\mathrm{K}$ 리그보다 높은 시장 가치를 보이고 있다. 이는 노 동력 공급 과잉으로부터 해외 이주를 선택해야 하는 국내 축 구선수들에게는 동남아시아 축구 시장이 경력 유지를 위한 대안으로 다가온 것이다. 추가로 국내 프로축구의 노동력 공 급 과잉은 $\mathrm{K}$ 리그 구단의 재정 악화 및 선수단 규모와 결부되 어 보다 많은 국내 선수들의 비자발적 이주를 야기하고 있음 을 확인했다.

이처럼 공급과 수요의 불균형 현상은 $\mathrm{K}$ 리그 구단의 재정 악화와 함께 한국 축구선수들이 해외 이주를 선택할 수밖에 없는 추진 요인(push factor)으로, 동남아시아 축구리그는 이주 목적지로서 유인 요인(pull factor)으로 작용하고 있 다. 그들의 경력을 유지하기 위해서 이주는 불가피한 선택이 다. 그리고 이러한 형태의 이주는 위의 통계 자료를 통해서 도 유추해볼 수 있듯이 다른 종목에 비해 프로축구시장에서 더욱 두드러지게 나타나고 있다. 결국, Miller et al.(2003) 가 스포츠 노동 이주의 한 예로 주장한 '스포츠 노동의 과잉 생산'이 한국 프로축구시장과 국내 선수들의 동남아시아 국 가로의 이주 사례에서도 예외가 아님을 방증하고 있다.

\section{스포츠 노동 이주와 제도 및 문화}

\section{1) K리그의 로컬룰(local rule): FA보상금제도}

소속클럽과의 계약 기간이 만료된 선수가 FA자격을 얻는 것은 프로스포츠시장에서 일반적인 상식이다. $\mathrm{FA}$ 를 취득한 선수는 어떠한 제약 없이 다른 구단과 새로운 계약을 체결할 수 있는 자유 권리를 가지게 된다. 국내프로축구리그에도 
$\mathrm{FA}$ 라는 용어가 규정 및 사용되고 있지만 자세히 살펴보면 온 전한 자유가 아니다(Myung \& Park, 2020). 표면적으로는 이적료가 발생하지 않는 선수로 이해할 수 있으나 국내 프로 축구에서 규정한 $\mathrm{FA}$ 선수는 이적 상황에서 보상금(또는 이적 료)이 합법적으로 발생한다. 이른바 FA보상금제도 때문이다.

본 연구는 참여자들의 이주 요인 중 하나로 FA보상금제도 를 발견하였다. FA보상금제도는 국내 프로축구구단간 이적 에 상당한 제약으로 기능하는 것으로 나타났으며, 이는 K리 그 이적 시장의 침체를 야기함과 동시에 국내 선수들을 해외 리그로 밀어내는 추진 요인으로 작용하였다. 물론 로컬룰이 기 때문에 해외 이주 시에는 적용되지 않는다. 이러한 이주 사례는 자발적인 이주보다는 비자발적인 선택인 경우가 더 많은 것으로 확인되었다.

그동안 프로스포츠 시장에서 계약 기간이 만료된 선수에게 이적료를 요구하는 행위는 일반 사회에서의 직업 선택의 자유 를 넘어 인권 침해와 동일하게 취급해왔다(Chang, 2011). 그 대표적 사례로 1975년 미국 메이저리그의 '보류 조항' 폐지, 1995년 유럽사법재판소의 '보스만 판결' 등이 있다(Hill \& Spellman, 1983; Simmons, 1997). 이처럼 K리그에만 존 재하는 FA보상금제도는 보편적 가치로서 인권을 중시하는 국 제 사회의 흐름에도 위배된다. Myung \& Park(2020)은 FA 보상금제도에 대한 법리적 해석을 통해 해당 제도가 대한민국 헌법에서 규정하는 '직업선택의 자유' 와 '행복을 추구할 권리' 의 측면에서 위헌성이 있다고 언급하였다. 선수 이주 문제뿐 만 아니라 리그 운영의 정상화를 위해서라도 FA보상금제도는 전면 폐지 또는 개정되어야 마땅하다. 이를 통해 FA선수들의 이적에 관한 선택의 자유와 권리를 보장하고 $\mathrm{K}$ 리그 내 이적 시장의 재활성화를 기대할 수 있을 것이다.

\section{2) 한국의 위계적 집단 문화}

연구 결과, 위계적 집단 문화 역시 이주 요인 중 하나로 발견 되었다. 지도자와의 의사소통 단절, 합숙훈련의 폐쇄적 일상, 경기결과에 따른 보복 행위, 구단 내 파벌, 선후배 간 상명하복 등이 K리그 구단 내부에 만연한 것으로 나타났으며, 이로부 터 벗어나기 위해 해외 이주를 선택한 사례도 있었다. 특히, 위계적 집단문화의 기피 현상은 이미 이주 경험이 있는 선수 들 사이에서 더욱 두드러지게 나타났으며, 국내로의 복귀 과 정에서 심리적인 걸림돌로 작용하였다. 이처럼 보다 자유로 운 운동장에서 훈련하기 위해, 보다 자유로운 환경에서 생활 하기 위해 $\mathrm{K}$ 리그 일부 선수들은 해외 이주를 선택하고 있다.
한국으로 이주한 하프-코리안 농구선수들의 삶을 연구한 Park \& Choi(2012)는 지나친 감독의 통제, 가부장제와 유 교사상에 기인한 대인관계, 합숙생활로 인한 제한된 사생활 등이 연구 참여자들에게 부정적으로 인식되고 있음을 확인 하였다. Lee \& Lee(2009:39) 또한 "한국의 스포츠 조직 문 화는 다른 여타 조직에 비해 강압적이며 엄격한 선후배 관계 가 형성”되어있다고 주장하면서, 이에 대한 원인으로 유교사 상을, 문제점으로는 폭력 관행을 언급하였다. 이들의 연구 결과는 본 연구 대상인 $\mathrm{K}$ 리그에서도 동일하게 관찰되었으 며, 이는 한국 스포츠 문화의 실상을 반영해주고 있다.

스포츠 분야에서 위계적 집단문화를 국가의 고유문화로 서 수용해야 할 것인가, 아니면 개변 또는 배척해야 할 것인 가의 문제는 또 다른 독립된 연구 주제로서 깊게 다룰 필요가 있다. 그러나 본 연구는 국내 스포츠 현장에서 발생한 각종 인권 문제들은 위계적 집단문화로부터 야기되었다는 다수의 연구들(Choe, 2009; Kim, 2016; Lee \& Lee, 2009; Yoon, 2011)을 지지하면서 개변의 필요성을 주장한다. 구 체적으로 국내 스포츠 주체들은 그동안의 잘못된 관행에 대 해 자발적 개선 의지를 보여야 할 것이며, 스포츠 기관 및 상 위 통제 기관들은 법제도적 장치를 마련해야 할 것이다. 이 러한 문제의식과 실천적 노력이 누적된다면 친인권적인 한 국 스포츠 문화를 기대할 수 있을 것이다.

\section{결론 및 제언}

국내 스포츠 선수 특히, 프로축구선수들의 해외 이주는 언 론 보도를 통해 쉽게 발견할 수 있지만 그 보도 사례는 극히 제 한적이다. 언론을 통해 대중에게 공개된 이주 사례들은 주로 유럽 국가와 일본 및 중국으로의 이주, 즉 주류 선수들의 자발 적 이주에 해당하기 때문이다. 이러한 보도 경향은 스포츠 노 동 이주가 신고전주의 경제학이나 신이주경제이론과 같이 경 제적 측면에서만 논의되어온 사실에 상당한 기여를 하였다. 실제로 그동안 우리는 특정 선수의 이적료와 연봉 수준에만 주목한 나머지 스포츠 노동 이주에 관한 사회학적 상상력을 발휘하는 데에는 비교적 소홀해왔다. 그 탐구 대상이 사회구 조적 요인이든 행위자 측면에서의 동기이든 간에 말이다.

그러나 스포츠 노동 이주의 형태는 여러 관점에 의해 분류 될 수 있으며, 그것이 무엇인가에 따라서 다양한 논의가 가 능해진다. 이에 본 연구는 주류 스포츠선수들의 이주 사례를 
거시구조적 관점(마르크스주의적 구조주의, 신고전주의 경 제학, 글로벌 아웃소싱)에서 설명한 기존 선행연구들과 달 리, 상대적으로 주목받지 못했던, 어쩌면 언론 보도에서 조 차 외면했던 비주류 선수들의 이주 사례를 연구 주제로 선정 하였다. 그 결과, 연구 참여자들의 동남아시아 국가로의 이 주를 비자발적 이주로 규정함으로써 그동안 연구 주제로부 터 소외되어온 국내 스포츠 노동 이주에 관한 학술적 및 실천 적 논의를 제공할 수 있었다.

스포츠 노동 이주를 자본주의 구조 아래 착취의 한 형태로 바라보는 마르크스주의적 구조주의와 이주 국가(여기서는 리그 또는 구단) 간 이해관계로 설명하는 글로벌 아웃소싱, 그리고 이주 요인을 개인 소득의 격차에서 찾는 신고전주의 경제학 등 기존 연구들이 제공한 이론적 틀은 본 연구 사례를 설명하는 데 한계가 있었다. 이에 본 연구는 추진-유인 이론 을 차용하여 노동의 공급과 수요 불균형으로부터 연구 참여 자들의 비자발적 이주에 관한 이론적 틀을 보완하였다. 이는 국내 스포츠 노동 이주에 관한 학술적 논의와 기초적인 분석 틀을 제공했다는 점에서 그 의의가 있다.

추가로 $\mathrm{K}$ 리그 로컬룰(FA보상금제도)과 위계적 집단 문화 역시 귀납적 분석을 통해 이주 요인으로 발견하였으며, 이들 요인은 $\mathrm{K}$ 리그의 이주 정책 및 제도, 한국 스포츠 문화에 관 한 실천적 논의를 제공하였다. 이 역시 주류 선수들의 자발 적 이주 사례에서는 보고되지 않은 사실임과 동시에 국내 엘 리트 스포츠 체계의 특수성(local context)을 반영한 결과 이다. 다만 $\mathrm{K}$ 리그의 로컬룰과 하위문화에 관한 논의를 본 연 구 주제(이주 요인)로 제한하여 폭넓게 다루지 못한 점은 한 계로 인정하고, 후속 연구의 과제로 남겨두고자 한다.

끝으로 본 연구는 스포츠 노동 이주 역시 사회 현상으로 간주되며, 특정 사회(집단)의 단면을 반영한다는 사실을 확 인하였다. 무엇보다도 국제학계와 달리, 그동안 스포츠 노동 이주에 주목하지 못했던 국내 스포츠사회학의 탐구 대상으 로서 그 가치와 필요성을 확인하였다. 스포츠 노동 이주를 통해 특정 사회의 내·외부 경제(시장) 구조와 관련 정책 및 제도를 바라보는 다양한 관점을 제공할 수 있으며, 보다 좁 게는 행위주체측면에서의 이주 동기(하위문화)를 이해할 수 있음을 시사한다. 따라서 본 연구에서 주목한 이주 사례(남 성 프로축구선수들의 동남아시아로의 이주 현상)뿐만 아니 라 다양한 종목, 이주 국가, 참여자, 이론적 틀, 방법론을 채 택하여 선수 개인의 이주 사례로부터 사회학적 의미를 탐색 하는 지적 노력이 지속되길 기대해본다.

\section{참고문헌}

Ahn, J. S. \& Kang, J. H. (2016). The Effect of Material and Experiential Goods on Foreign Athletes' Adaptation: A Case Study of Korean Professional Soccer. Korean Journal of Sport Management, 21(1), 51-62.

Baur, D. G., \& Lehmann, S. (2007). Does the Mobility of Football Players Influence the Success of the National Team?. Institute for International Integration Studies Discussion Paper no. 217.

Braun, V., \& Clarke, V. (2006). Using Thematic Analysis in Psychology. Qualitative Research in Psychology, 3, 77-101.

Brill, C., \& Nin Siriwat, C. (2016). Chao Amigos! Hello Thailand: football, migration and sustainability in Thailand. Soccer \& Society, 17(5), 680 - 691.

Chang, M. (2011). Legal Issues of Sports Player Transfer upon Player Contract's Expiration -Focused on Compensation for Free Agent's Transfer-. Chosun Law Journal, 18(3), 113-141.

Choe, B. M. (2009). The Type of Sports Violence and It's Countermeasure. The Journal of Sports and Entertainment Law, 12(4), 257-278.

Choi, S. H. (2004). The Societal Democratization in Korea: Focusing on the Analysis of the NHRC. Journal of Social Development Studies, 10, 115-151.

Darby, P. (2007a). African Football Labour Migration to Portugal: Colonial and Neo Colonial Resource. Soccer \& Society, 8(4), 495-509.

Darby, P. (2007b). Out of Africa: The Exodus of Elite African Football Talent to Europe. The Journal of Labor \& Society, 10(4). 443-456.

Darby, P., Akindes, G., \& Kirwin, M. (2007). Football Academies and the Migration of African Football Labor to Europe. Journal of Sport and Social Issues, 31(2), 143-161.

Do, Y. I. (2016, Jan 21). The first deficit since the founding of POSCO, Jeonnam and Pohang who cope with crisis of parent company. The Daily Sports Seoul. Retrieved from http: //www.sportsseoul.com/news/read/347700

Earley, P. C. (1989). Social Loafing and Collectivism: A Comparison of the United States and the People's Republic of China. Administrative Science Quarterly, 565-581.

Elliott, R. \& Harris, J. (2011). Crossing the Atlantic from Football to Soccer: Preliminary Observations on the Migrations of 
English Players and the Internationalization of Major League Soccer. The Journal of Labor \& Society, 14(4), 557-570.

Elliott, R. (2013). New Europe, new chances? The migration of professional footballers to Poland's Ekstraklasa. International Review for the Sociology of Sport, 48(6), 736-750.

Elliott, R. (2016). Football's Irish Exodus: Examining the Factors Influencing Irish Player Migration to English Professional Leagues. Internation al Review for the Sociology of Sport, 51(2), 147-161.

Elliott, R., \& Maguire, J. (2008). Thinking Outside of the Box: Exploring a Conceptual Synthesis for Research in the Area of Athletic Labor Migration. Sociology of Sport Journal, 25(4), 482-497.

Hatch, A. J. (2002). Doing Qualitative Research in Education Settings. Albany: State University of New York Press.

Heo, H. M, Hwang, J. I., \& Sun, B. Y. (2008). Recognitions of Female Leaders about Sexual Harassment and Abuse of Female Athletes. Korean Society for the Sociology of Sport, 21(2), 301-421.

Hill, J. R., \& Spellman, W. (1983). Professional Baseball: The Reserve Clause and Salary Structure. Industrial Relations: A Journal of Economy and Society, 22(1), 1-19.

Hofstede, G. (1984). Culture's Consequences: International Differences in Work-related Values (Vol. 5). CA: Sage Publications.

Jo, S. S., Maeng, I. S., \& Lee, W. Y. (2014). Study on Emotional Revelation of Sport-Fans according to Conflict between Professional Athlete and One"s Club about Transfer of Oversea Country. Korean Journal of Physical Education, 53(4), 131-142.

Jo, Y. H. (2014). Migrating Sports Celebrity and Flexible Citizenship: Media Representations of Tang Yeo-so during the 2008 Beijing Olympic in South Korea and China. Korean Journal of Sociology of Sport, 27(4), 217-241.

Jo, Y. J. (2011). Study on the Image Reception of Foreign Athletes in Professional Baseball League. Master's Dissertation. Hanyang University.

Jung, B. O. (2016, Nov 1). Hanhwa baseball team fans said 'Kim who infringe on players' human right should resign from manager". The Dong-A Ilbo. Retrieved from http://news. donga.com/3/all/20161101/81107473/2

Kim, D. K., \& Park, B. Y. (2014). Study on the efficient marketing mix (7P) management of $\mathrm{K}$ league clubs. Korean Journal of Sport Management, 19(6), 133-155.

Kim, H. (2014, Apr 28). TPL's broadcasting rights fee, three times the K-League. Footballist. Retrieved from http://www.footballist.co.kr

Kim, H. S. (2016). Sports \& Human Rights in Korea: Age of Violence towards Victory. Korean Journal of Physical Education, 55(6), 1-9.

Kim, I. H. (2010). The Approach of Integrated Methodology for the Recognition, Current Status and Cause of Sexual Harassment in Sports. Korean Society for the Sociology of Sport, 23(3), 55-79.

Kim, J. K. (2015, Jul 11). Exodus to China and the Middle East. Mydaily. Retrieved from http://www.mydaily.co.kr

Kim, M. C. (2013). Study on Managerial Background of Provincial and Municipal Professional Soccer Teams by Analyzing Financial Ratios. Korean Journal of Sport Management, 18(6), 87-101.

Kim, U. C. (2000). The Scientific Foundation of Indigenous and Cultural Psychology. Korean Psychological Journal of Culture and Social Issues, 6(3), 1-24.

Kim, Y. E., Moon, B. R., \& Kim, B. S. (2014). Semantic Interpretation of Newspaper Report on Victor An in 2014 Sochi Winter Olympic Games: Ahn Hyeon Soo to Victor An. Korean Journal of Sociology of Sport, 27(2), 77-102.

Kim, Y. M. (2016). A Study on Recognition of the Naturalized Athletes, National Identity, and the Selection of National Athletes. Unpublished Master's Dissertation. Hanyang University.

Kline, D. S. (2003). Push and Pull Factors in International Nurse Migration. Journal of Nursing Scholarship, 35(2), 107-111.

Korea Baseball Organization. www.koreabaseball.com

Korea Professional Football League. www.kleague.com

Korea Volleyball Federation. www.kovo.co.kr

Korean Basketball League. www.kbl.or.kr

Korean Olympic Committee Sport Support Portal. www.sportsg1.or.kr Kwon, S. Y., \& Lim, S. W. (2012). Docility Aspect of College Elite Female Football Players to the Power of Head Coach. Korean Society for the Sociology of Sport, 25(4), 109-125.

Lee, C. W. (2013). Qualitative Research Method in Leisure Studies. Seoul: Rainbow books.

Lee, E. H. (2012). Study on the Racial Attitude toward Foreign Athletes of Professional Baseball Fans. Master's Dissertation. Hanyang University.

Lee, H. S. (2015, Dec 15). The change of professional baseball team Samsung through profession al football team Samsung'. 
Daily Sports. Retrieved from http://isplus.live.joins.com Lee, J. H. (2015, Jul 14). K league Exodus, No Answer. Sports Hankook. Retrieved from http://sports.hankooki.com

Lee, J. M., \& Shin, B. D. (2014). Sexual Violence against Student Athletes and Civil Liability of School Authorities -Focus on Comparing American Law-. The Journal of Sports and Entertainment Law, 17(3), 59-88.

Lee, N. M. \& Lee, H. G. (2009). A Study of Socio-Cultural Backgrounds and Problems about the Taming of the Freshmen in Physical Education Department and the Method of Its Improvement. Korean Society for the Sociology of Sport, 22(4), 19-43.

Lee, N. M. (2010). The Phenomenon of Sports Labor Migration and Manifestation of Flexible Citizenship in Korea. Korean Journal of Sociology of Sport, 23(3), 155-178.

Lee, S. B. (2010). Global Outsourcing: A Different Approach to an Understanding of Sport Labour Migration. Global Business Review, 11(2), 153 - 165.

Lee, S. F. (2015, Feb 4). MP \& Silva in for the long term, says Managing Director. FourFourTwo. Retrieved from https://www.fourfourtwo.com

Lim, K. H. (2015, Jul 16). Reality of K league which Its players move to China's Second League. Best Eleven. Retrieved from http://sports.ne ws.naver.com

Lincoln, Y. S., \& Guba, E. G. (1985). Naturalistic Inquiry. CA: Sage Publications.

Magee, J., \& Sugden, J. (2002). The World at Their Feet: Professional Football and International Labour Migration. Journal of Sport and Social Issues, 26(4), 421-437.

Miller, T., Rowe, D., McKay, J., \& Lawrence, G. (2003). The Over-production of US Sports and the New International Division of Cultural Labor. International Review for the Sociology of Sport, 38(4), 427-440.

Molnar, G. (2006). Mapping migrations: Hungary related migrations of professional footballers after the collapse of communism. Soccer \& Society, 7(4), 463-485.

Myung, W. S., \& Lee, J. Y. (2018). The Changes of Paradigm in Sports Labor Migration and Its Significance: Focused on Korean Footballers. Korean Journal of Physical Education, 57(5), 105-123.

Myung, W. S., \& Park, K. H. (2020). Legal and institutional consideration on FA compensation system of Korean professional football league. Korean Journal of Sport Science, 31(3), 459-474.

Myung, W. S., \& Won, Y. S. (2019). Korean footballers' exodus and its factors: Player migration to China and the Middle East. Korean Journal of Sport Science, 30(1), 45-59. Myung, W. S., Won, Y. S., \& Koo, S. K. (2015). A Study on K league Players' Perception and Preparation Process on Retirement. Korean Journal of Sport Science, 26(2), 254-266.

Park, C. B., Seo, J. H., \& Kim, K. C. (2012). Ethnographic Approach for the Culture of Collegiate Boxing Player's Training Camp Life. The Korean Society of Sports Science, 21(1), 193-204.

Park, J. M. \& Choi, Y. L. (2012). Sport Philosophy: Being KBL Player: Perceiving Own Identity of the Half-Korean Basketball Players throughout Discord and Adaptation on Korean Athletic Culture. Philosophy of Movement: Journal of Korean Philosophic Society for Sport and Dance, 20(3), 165-184.

Patton, M, Q. (2002). Qualitative Research and Evaluation Methods (3rd ed.). CA: Sage Publications.

Ravenstein, E. (1889). The Laws of Migration: Second Paper. Journal of the Royal Statistical Society, 52(2), 241-305.

Roderick, M. (2013). Domestic Moves: An Exploration of Intra-national Labour Mobility in the Working Lives of Professional Footballers. International Review for the Sociology of Sport, 48(4), 387-404.

Simmons, R. (1997). Implications of the Bosman Ruling for Football Transfer Markets. Economic Affairs, 17(3), 13-18. Siriwat, N., \& Brill, C. (2015). Football, Migration and Sustainability in Thailand. International Journal of Social Science and Humanity, 5(8), 707-713.

So, W. H. (2010). Leader's Influence on Members` Information Sharing Pattern and Group Polarization. The Korean Journal of Area Studies, 28(3), 405-431.

Transfermarkt. www.transfermarkt.com

Yang, S. Y., \& Won, Y. S. (2007). Labor Migration and Adjustment Experience of Foreign Players in Korean Professional Basketball League. Korean Journal of Sociology of Sport, 20(3), 537-553.

Yin, R. K. (2014). Case Study Research: Design and methods. CA: Sage publications.

Yoon, S. M. (2011). The Present Condition, Regulation and Countermeasure on Sexual Assault in Sports. The Journal of Sports and Entertainment Law, 14(1), 59-84. 


\title{
남성 프로축구선수들의 비자발적 이주: \\ 왜 그들은 동남아시아로 떠나는가?
}

\author{
명왕성 \\ 한신대학교 조교수
}

[목적] 본 연구의 목적은 한국 남성 프로축구선수들의 동남아시아로의 이주 현상과 그 요인을 탐색하는데 있다. [방법] 이를 위해 국내 프로축구리그(K리그)에서 동남아시아 축구리그로의 이주 경험이 있는 선수 9명, 그들의 에이전트 4 명, $\mathrm{K}$ 리그 관계자 2 명을 대상으로 질적 사례연구를 실시하였다. [결과] 그 결과, 연구 참여 자들의 이주 사례를 비자발적 이주로 규정함으로써 그동안 소외되어온 비주류 축구선수의 노동 이주에 관한 학술적 및 실용적 논의를 제공하였다. 추진-유인 이론을 차용하여 노동의 공급과 수요 불균형으로부터 연구 참여자들의 비자발적 이주에 관한 이론적 틀을 보완하였다. $\mathrm{K}$ 리그 로컬룰(FA보상금제도)과 위계적 집단 문화 역시 귀납적 분석을 통해 이주 요인으로 발견되었으며, 이는 주류 선수들의 자발적 이주 사례에서 보고되지 않은 사실임과 동시에 $\mathrm{K}$ 리그의 특수성(local context)을 반영한 결과이다. [결론] 본 연구는 스포츠 노동 이주 역시 사회 현상으로 간주되며, 특정 사회(집단)의 단면을 반영한다는 사실을 확인하였다. 이는 스포츠 노동 이주를 통해 특정 사회의 내·외부 경제(시장) 구조와 관련 정책 및 제도를 바라보는 다양한 관점을 제공할 수 있으며, 보다 좁게는 행위주체측면에서의 이주 동기(하위문화)를 이해할 수 있음을 시사한다.

주요어: 스포츠 노동 이주, 비자발적 이주, $\mathrm{K}$ 리그, 동남아시아 축구리그, 축구선수, 이적, 질적 사례연구 